Shirwadkar, Swati (2018): Domestic Violence and the Implications of Belonging: Experiences of Indian Immigrant Women in North America. In: Elfriede Hermann and Antonie Fuhse (eds.): India Beyond India: Dilemmas of Belonging. Göttingen: Göttingen University Press (Göttingen Series in Social and Cultural Anthropology, 12), pp. 175-193. Doi: 10.17875/gup2020-1269

\title{
9 Domestic Violence and the Implications of Belonging: Experiences of Indian Immigrant Women in North America
}

\author{
Swati Shirwadkar
}

This chapter explores the experiences of domestic abuse by female Indian immigrants in North America, who are caught between multiple layers of constraints emanating from the host community on the one hand, and from belonging to the homeland culture on the other. Deprived of access to a violence-free safe space in their private lives, these women attempt to pull off a delicate balancing act between life, family and culture in the western world.

Cultural diversities due to increased transnational migration have attracted the attention of researchers in recent years, bringing out the several dimensions of the process as well as the multiple challenges, including that of assimilation into the host society. The social cost of migration, particularly for women, is one area that still needs attention. Exclusion of immigrants from policies and programs, particularly in the case of women, remains an area of concern for both policy makers and activists. This is particularly true for domestic violence against women. Gender-based violence within the private area of the family household is a universally acknowledged problem in many societies the world over. However, developed nations, particularly North America and Europe, have taken substantial policy and programmatic steps to reduce violence against women, especially within the family. Given the recent trends of immigration to these countries, there is a growing concern whether these policies and programs are useful for accommodating the needs of immigrants, and indeed addressing the issue of cultural diversity. This perceived shortcoming espe- 
cially warrants attention in the case of North America, i.e. Canada and the United States. What, therefore, are the experiences of Indian immigrant women that render it problematic for them to access the benefits of existing policies and programs?

To explore this issue, I will first present a review of studies on domestic violence and the Indian cultural context. With this general background in place, I contextualize domestic violence against immigrant Indian women living in Canada and the United States in terms of their belonging to the homeland culture. This will bring out the complexities of how Indian immigrant women experience domestic violence - first in the immediate family context, second in terms of general diasporic experience, and third in terms of belonging to a particular homeland culture. In a further step, I summarize this exploratory study of age-stratified immigrant Indian women, social service workers and the wider community, revealing the constraints preventing these women from accessing programs and policies that have been put in place to protect them. The conclusion suggests a need for further research into the problematic of what it means for an immigrant diaspora to belong to a homeland culture. The study highlights how immigrants struggle to become part of the host society, suggesting that full access to policies and programs designed to help has yet to be achieved.

\section{The Issue of Domestic Abuse}

Violence against women is indisputably a universal phenomenon, being firmly rooted in different societies and cultures all over the world. Most tragically, domestic abuse often goes unnoticed or occurs behind closed doors. The family perspective did not see domestic violence as a universal phenomenon perpetrated against women (Gelles 1993; Gelles and Straus 1988). However, other research suggests that violence is asymmetrical and that women are persistently abused in developed and less-developed countries alike (Dobash and Dobash 2005; Heise et al. 1994). The feminist perspective sees wife abuse as an extreme form of male domination as well as a socio-historical reality rooted in the structure of patriarchy, pointing to gender differences in patterns of domestic violence. Women are without power in social, economic or political spheres of life, rendering them dependent and vulnerable (Dobash and Dobash 2005).

Although the feminist perspective has highlighted both the complexities of domestic violence and the institutionalization of gender inequalities, it fails to adequately address other factors behind the subordination and entrapment of women (Fernandez 1997). Recent studies draw attention to factors transcending gender, which are of particular importance for the study of South Asian communities. M. Jacqui Alexander and Chandra Talapade Mohanty have emphasized the need to understand genealogies when analyzing women's experiences (Alexander and Mohanty 1997). The use of ethnicity and gender as significant analytical categories has been deemed necessary to contextualize domestic violence among immigrant communities (Abra- 
ham 1999). Especially in the case of South Asian women, there is a need to be sensitive to the place of origin of immigrant communities. Yet this sensitivity is frequently either missing or downplayed by state policy. Analysis of the complicated nature of domestic violence in immigrant families points to the involvement of multiple interfacing factors like cultural conditioning, racial prejudice, isolation, and immigrant status (Abraham 2000). Thus it is imperative to move beyond a feminist perspective when exploring domestic abuse against South Asian immigrant women.

\section{Method}

This exploratory study was conducted to identify more specifically the experiences and needs of Indian immigrant women living in Canada (and to some extent in the United States as well) (Shirwadkar 2004). The current programmatic approaches and policy provisions are contrasted with the actual experience and culture of the abused women. I conducted in-depth interviews with a snowball sample of Indian immigrant women, in order to identify the issues, barriers, and problems they encounter when dealing with domestic violence in the Toronto area and the Southern United States; likewise, I conducted telephone interviews with women from other parts of the United States. Additional interviews with battered women advocates, activists, and prominent community social workers were also used to substantiate and elaborate on the interviews with the immigrant women. There were inevitable limitations, first of all due to the shortness of my in-country stay (however, after a gap of some ten years, I was able to add some more recent cases, interviewing respondents while on visit in India or else by phone), and secondly due to the small number of observations drawn on, which necessarily reflect only the perceptions and experiences of a small group of immigrants. Notwithstanding, the findings suffice to outline the main issues facing immigrant women.

One of the main challenges when researching immigrant communities is gaining access to its members and obtaining disclosure on sensitive issues. As I belong to India, I was more readily accepted by the immigrant community and could attend a variety of formal and informal community activities. I was able to contact community residents and social workers in connection with celebrating Indian festivals and informal family get-togethers. Discussions and observations with these parties helped me understand the cultural milieu of the immigrant community and the perception of domestic abuse within the immigrant community. These gatherings also helped me understand the attitude of the immigrant community to domestic abuse. The meaning the community attaches to the issue of wife abuse is different from mainstream society. Certain forms of abuse are not only tolerated but may be considered legitimate (Rao 1998). Though most immigrant women admitted that domestic violence was a problem, they tended to ascribe the problem to a regional Indian community other than their own, especially when we discussed the issue in a community setting or in a large group. Moreover, prominent community social 
workers and activists privately elaborated actual cases of abuse among all the Indian communities. Some community members later privately approached me to narrate cases of abuse.

Information was sourced via a few domestic violence victims from immigrant communities in Toronto and the United States; respondents came from different parts of India and were chosen by snowball sampling. As already pointed out, I held an advantage in developing trust with these women by being from India myself. Also, the short period of my stay in Canada and the United States reduced their worry that I might leak their 'family problem' to the wider community. Thus, I benefited from being an 'outsider,' while gaining social access as an 'insider.' My interviews with the victims were unstructured and some were spread over time. Sometimes victims gave information about abuse on the telephone when their husband was not around, and sometimes they did it by email. In one case, the extended family of one victim found out that she was talking to someone about domestic abuse and put an end to her contacts.

In four cases, the abuse was physical, though combined with psychological, spatial, and financial abuse. Two cases involved severe physical abuse. In other cases, the abuse was more psychological and financial. However, it has to be noted that in the course of discussion most victims concurred that just a slap from the husband during an argument could be tolerated. None of these women had ever sought help from service providers. One of the physically abused victims eventually confided her problem to a community support group, while another was rescued by her maternal family members. Even among the physically abused, one victim did not want to end the marital relationship. (However, two of the victims had obtained a divorce.) In one case, the husband of the abused woman crosschecked if the wife was meeting with "the researcher."

\section{Domestic Violence in India}

Crime and violence against women in India has only recently attracted research attention, prompted in part by the Indian women's movement plus concern over issues like an increasing number of dowry deaths (Kumar 1993). In India, nearly two in five married women experience some form of violence from their husbands. The embedded (and structural) nature of violence against women has been captured by earlier studies of the status of women in India. These studies have also brought out the regional variations in women's status, reflecting local differences in social structure and institutions (Karve 1965; Madan 1975; Srinivas 1978; Committee on the Status of Women in India 1974). They have likewise exposed the impact of the patriarchal, joint family in imposing marriage customs and shaping the role of women.

An Indian woman traditionally faces a range of expectations associated with the principle of sewa (selfless service): proficiency in cooking elaborate Indian food, looking after in-laws, maintaining respectful and amicable relationships, entertain- 
ing guests, and providing a flow of gifts (Dube 2001). The construct of femininity emphasizes submissiveness, inferiority, docility and dependency, plus the importance of the patriarchal family (Shirwadkar 1998). Deviation from these gender role expectations are likely to meet with different forms of abuse, and lend some justification to domestic abuse as an inevitable part of marriage (Busby 1999; Rao 1998). However, there also exists an age and role hierarchy within Indian families, affording some women space depending on their role status. With concern growing over this issue, recent research in India has highlighted several correlates of domestic violence, such as young age at marriage, family hierarchies, poverty, and economic independence (Ahuja 1987; Fernandez 1997; Karlekar 1998; Kelkar 1992; Kumari 1989; Mahajan 1990; Rao 1998). Gender studies have brought out the class-caste context and the rural-urban variations in domestic violence. The latter context helps to elucidate how and why such indicators as education or employment may or may not work to reduce violence or dowry demands in some regions, and also why strategies adopted by women to subvert domination in different communities are more or less effective (Deolalikar and Rao 1998; Liddle and Joshi 1986; Mukherjee, Rustagi and Krishnaji 2001; Raheja and Gold 1996).

Indian women, moreover, face another problem: the scarcity of policies and programs addressing domestic violence in India. Whereas counseling programs are court-mandated for men in North America, in India itself this is not the case - there the chief recourse for women is to seek help from family counseling cells, though they rarely in fact do so. There are also some government-sponsored housing facilities set aside for women fleeing violent relationships. A Supreme Court justice criticized that these facilities were being run like brothels (Sakal Daily 2001), supporting the impression that most state-sponsored programs are counterproductive. However, some policy improvement has materialized through recent legislative amendments and a proposed domestic violence bill. Women's organizations have, however, raised several reservations against the prospective bill. Apart from problems in defining domestic violence, the bill did not clearly give the women the crucial right to remain in her matrimonial home (The Lawyers Collective 2001). Finally, the Prevention of Domestic Violence against Women Act was passed in 2006 after many changes, yet on the level of implementation many hurdles remain.

This cultural context of domestic abuse in India may prove helpful for analyzing the abuse experienced by Indian immigrant women. Here violence within the family has to be situated within the larger context of womanhood in Indian culture generally - a culture undergoing turmoil, transition, and reassertion in the era of globalization. The experience of the Indian immigrant woman is complicated, however, not only by her homeland culture, but also by her immigrant community and the new nation where she resides (Bhattacharjee 1997). This social complexity and cultural specificity has led South Asian activists and researchers to voice their dissatisfaction with the mainstream battered women's movement, which tends to focus on only one dimension of these women's lives - the violent relationship (Alexander and Mohanty 1997; Bhattacharjee 1997). 


\section{Diaspora and Belonging: Immigrants and Culture}

Immigrants who still see themselves as belonging to a homeland cultural context also see themselves as constituting a diaspora. The identity of diaspora ethnic groups is rendered more dynamic by increasing mobility in the present globalization context (Appadurai 1997). Globalization and increasing migration have brought into focus complexities in the notion of boundaries and loyalties, especially in terms of belonging and identity (Koh 2011). The new diaspora, now being lived out in western countries, reproduces its existence through the perceived fact of still belonging to the home culture on the plane of life practices, albeit in different circumstances. The impact of community is strong among these immigrants, even if it is an imagined community (Anderson [1983] 2006).

It is acknowledged that multiple identities coexist in the case of immigrant diasporas (Anthias 2006). In their working lives Indian Americans strive to be perfect professionals, instilling in their children the American values of competitiveness and hard work; but at the same time they are at pains to socialize their children in the traditional Indian culture to which they belong, through visits to temples, missions, voluntary community language schools, and - importantly for our present concern they expect their daughters and wives to comply with traditional roles, as for example when entertaining guests with Indian food or taking part in festival rituals. Research studies show that there are shifts in beliefs and identity in the new context (Joshi 2006; Segady and Shirwadkar 2012); hence identity can be flexible. To belong to any collectivity, it is important to conform to the prevalent gender norms (Anthias 2006). The culture of the ethnic population is not a reified but a dynamic construct. In the Indian context for example, while the core beliefs and values may not be easily erased (Singh 2000), provision is made for new adaptations. Increasing entry of Indian immigrants into the western world does not necessarily mean that the cultural roots expressed in core institutions like family, kinship, marriage, and motherhood are forgotten. On the contrary, they are reconstituted and used from time to time, albeit for different purposes. The institutional impact remains strong, especially in the cases of the extended family, kin network, and marriage customs (Karve 1965; Madan 1975; Srinivas 1978). Sociocultural and family obligations, the norms and values of a particular culture, are significantly implicated in people's life cycles, and this applies no less to the immigrant context, with the difference that they now need to be reconstituted in a rather different situation to their place of origin.

In the altered circumstances of immigration, women may not necessarily be aware of the nuances of western legalities, especially those relating to the private sphere, which in most South Asian countries is usually treated as a sacrosanct area; as a result, legal measures are only considered as the last option; moreover, mediation through the larger family-kin network is preferred over social welfare services. Though welfare services are common in western countries, certainly compared to the South Asian scene, social service workers may be handicapped by a paucity of understanding or information about the situation of immigrant Indian women (Status 
of Women Canada 2002). In the Indian context, issues relating to marital discord are considered personal and emotional, a stricture that also applies to the cultural socialization of women, which traditionally includes complex layers of family-kin networks along with ethnic community ties. Explicating the concept of belonging, Nira Yuval-Davis brings out its different levels, which include social locations, emotional attachments to collectivities, and also to a value system that helps judge others from the perspective of the collectivity (Yuval-Davis 2006). The complex interplay of these layers needs to be unraveled, if we are to understand the issue of abuse and the effort to overcome it.

\section{Indian Immigrant Women in Canada and the United States}

The presence of the Indian immigrant community is strongly felt in some parts of Canada and the United States. Especially Ontario or British Columbia and California or Texas are known to have skilled Indian IT professionals. Toronto, which is in Ontario province, possesses the largest population of Indian immigrants $(554,900$, or $4.9 \%$, of Ontario's total population). An Indian woman usually comes to Canada in circumstances where she is totally dependent on her spouse; and in most cases, she is unaware of the immigration laws. Her usual close-knit kin and extended family network, along with her neighborhood support and community resources, are suddenly lost or substantially reduced (Bannerji 2000; METRAC 2001). Consequently, she becomes very isolated. In some cases, this isolation results in a compensating control exercised by her husband that has psychological, physical, financial and even spatial aspects. Studies indicate that enforced dependency can be predictive of intimate partner violence (Raj and Silverman 2007). Owing to cultural barriers, she cannot speak about her abuse in public or seek assistance elsewhere. Indian women, particularly those from middle-class backgrounds, are ashamed to admit to domestic abuse because of the social stigma attached to it and the fear of 'gossip,' especially within the community (Johnson and Johnson 2001; Raheja and Gold 1996). They do not seek help from shelter homes for abused women, because of the Indian woman's traditional preference for turning to her natal family for support rather than some outside agency (Desai \& Krishnaraj 1987; Preisser 1999). Patriarchal family norms are predominant even in urban nuclear families in India, while in the immigrant context the community takes the place of the neighboring kin group (Pillai 2001; Segal 1999; Uberoi 2000).

An Indian middle-class woman is seldom educated about her legal rights as a 'wife.' Innumerable cultural symbols, such as the pan-Indian epic character of 'Sita' or 'Sati-Savitri' (idealizing the quiet suffering of women), ingrain the belief that the marital family home is a woman's only alternative (Epstein 1996; Kakar 1978; Segal 1999). Indian immigrant women often also stay in abusive relationships because of scant economic resources and language barriers; conversely, social service workers 
generally do not have enough information or understanding of Indian immigrant women to effectively reach out to them (Status of Women Canada 2002).

\section{Policy Provisions and Experiences of Immigrant Women in Canada and the United States}

Canada and the United States have put in place several policies and programs to prevent domestic violence against women. In the case of immigrants, however, the legal situation for domestic abuse victims is rather more complex (Abraham 2005; Dasgupta and Warrier 1996). The data on transition houses in Ontario showed that the majority $(80 \%)$ of beneficiaries of subsidized housing are Canadian-born. It was observed that a shelter home in the Houston area did not have any South Asian victims. Moreover, the data showed that there was no separate category for South Asians. This reflects a need by Indian women to remain in a secure community network.

One Indian immigrant woman gave her impressions after visiting a shelter home. All her fears of 'loose' western morals, lesbianism, and racist discrimination surfaced, and she did not dare to even think of leaving her home again, even if her husband was an abuser. The immigrant culture was seen as too different and the western culture as too 'modern,' combined with a fear of race relations along the grid of power. Obviously, the subjectivities attached to the issue have been used to build a defense wall, where 'our' culture is constructed as superior, at least in terms of moral conduct, than 'theirs.' The identity of the 'other' may be an imagined one. In this case the generational difference also mattered, as the victim was an elderly person. She also commented that at her advanced age, interacting with the young social worker at the shelter seemed very odd and put her in the awkward situation of asking for help; besides, the social worker seemed 'so formal,' which might mean she was not genuinely interested in her problem.

Clearly, it is not easy for South Asian women to interact with members of the host community in these matters. Moreover, a Canadian social worker of South Asian origin admitted that racism existed even within the social service organizations dedicated to helping women. Subsidized housing in Canada was deemed inadequate, given the great demand and a 10-year waiting list.

\section{The Tug of the Home Culture and Belonging to Family in India}

It was observed among the immigrant Indian women interviewed for this study that there was a predominant feeling of belonging to the home culture and tradition. A woman's identity in India is constructed from several complex and dynamic factors. It is influenced by primordial loyalties such as religion, caste, language, and history, combined with such cultural specifics as particularized beliefs, customs, traditions, and values. All of which are ingrained in a process of socialization via local languages 
and literature, Hindi movies, and the invasion of satellite TV (Chanana 1996; Derné 1999; Kishwar 1999; Segal 1999). On the one hand, there is the mystification of sexuality due to rigid segregation of the sexes in public life; on the other hand, there is the ensemble of marriage ceremony, dowry and gifts - all of which reinforce the subjugation of women within the Indian patriarchal social structure.

Browsing through the matrimonial columns of the major national daily 'The Times of India' elucidates the importance of marrying into a 'status' family, preferably 'NRI' (non-resident Indian). These practices pressure women into keeping their marriages intact. For example, two abused women interviewed in this study told of 'telephone marriages' with second-generation South Asian Canadians of a particular religious community, where the actual presence of the bridegroom at the wedding was not necessary. The young women said that they were happy with their family's decision to have them marry a person whom they had not even seen at the time of the wedding. "If something unfortunate happens then that is my fate," one of them said.

Some practices in India, such as the dowry, cross the boundaries of religion or caste. As an impact of consumerism, some castes and tribes are even adopting the dowry, although it was never a part of their tradition. The spread of education and women's employment has not changed their dowry situation appreciably, although in some cases educated young men now carry a higher price tag. If a young man is already an immigrant, this will almost certainly cause an increase in his dowry price. Dowry has become a continuous source of cash extraction, with different forms of gifts answering to the need to acquire consumer goods, nor does this need for capital cease after marriage (Deolalikar \& Rao 1998; Jejeebhoy 1998).

Ending such a marriage means returning to one's family, not only with the shame and stigma of divorce, but with the added disgrace of having wasted all the money spent on the marriage. Usually Indian women do not want to leave a marital relationship because marriage is seen as a lifelong relationship, or as a sanskar or sacrament (Agnes 2000). Even in India, there is a tendency to encourage and almost force young women to suffer abuse in the marital family - anything but ceasing to live with their in-laws and husband. Divorce is usually discouraged as it amounts to a loss of family honor (Kallivayalil 2010). Canadian television telecast a Canadian Indian arranged marriage that was opulently celebrated, but ended sadly in the wife killing the husband in a scuffle. The woman's in-laws' attempted to control the son, provoking him to physically assault the wife, who then defended herself. Ending a marriage by divorce is not an easy option for Indian women, even when they are abroad. The common perception in developed countries concerning arranged marriages is that they are, in effect, a trap attached to a culture that is barbaric. That the menace of domestic violence is all pervasive is easily forgotten. Extreme cases such as of honor killings are also reported in the media of the United Kingdom and the United States. Such reports, where the talk is of killing the wife to preserve the family honor, serve to revive earlier images associated with Indian culture - such as satee - resulting in a media frenzy of 'burning brides,' 'burning widows,' or the like. Media coverage 
and discourse problematizes incidents such as honor killing, so much so that even arranged marriages are portrayed as barbaric and ending in violence. However, if something similar happens in the host community (e.g., stalking and the killing of a partner on suspicion), it is not treated the same way. The binaries created by the discourse on ethnicized culture (seen as emotional and backward) and the culture of the host society (seen as rational and advanced) exclude immigrants and further accelerate the 'othering' process.

Shelter workers reported that while South Asian women do seek counseling, they are also reluctant to leave even a highly abusive situation and avail themselves of shelters. Acceptance of a failed marriage is hard enough, but far worse is speaking about it in public. This can degrade one's self-image of being a 'good wife' and daughterin-law. Moreover, a 'failed marriage' is often accompanied by a loss of status and ties within the immigrant community, which, as has been pointed out already, serves as a support network for Indian immigrant women in an alien society. The fear of the losing one's immigrant status imposes an additional burden in the form of having to face one's community back home in India. An immigrant woman related how when she called one of her male colleagues, his wife had picked up the phone, since he was not at home at the time. In the course of the conversation the wife broke down and told the caller about the physical abuse she was enduring. But when given the contact details of a social worker as well as a shelter address, the victim blurted out the words: "hamare me aisa nahi karte na ... log kya kahenge!" "'but we don't do that, what will people say!"). The invisible idea of $\log$ (people) and the pressure of the invisible community clearly works, even in the new geographic locale. After this she never called back and avoided all contact. The sense of being a community member - adhering to its norms and not crossing red lines - seems strong among many immigrants. Besides, there is always community pressure coming from being part of a 'model minority' (Abraham 2005). Migration is often coupled with aspirations of upward mobility, hence immigrants need to balance awareness of how their actions will impact on the immigrant community with a wider awareness of how these same actions will be seen back in India, where immigrants enjoy the high status of 'NRI' (NRI, or 'non-resident Indians,' is the homeland term used in this connection). In such cases, identity must be constructed in relation to the imagined 'other' and by self-insulation, since one is also aware that getting help in the new social context is not easy. There may also be a role for the host community in constructing them as the 'other.' It was found that interaction with the host community in Canada and United States is mostly limited to the workplace. Family visits and community participation were almost absent. On the other hand, the Indian immigrant community is closely knit and interdependent, with a preference for engaging in collective leisure activities and community gatherings. There is also a lot of sharing of social capital via networks - e.g. accommodation for newcomers, monetary help, transport for visitors and children, or help with cooking. It is difficult for an Indian woman to cope without a community network of her own, especially when she knows that the kind of help she needs cannot be provided by the host community. 
For an immigrant woman, employment does not necessarily ease her lot. Having a job does not mean that housework is shared by the husband, nor is there any reduction in her duties to relatives. One middle-aged interviewee related that she still observes the Indian dress code, because of her mother-in-law's dictates and her husband's disapproval of western culture. Another lady jokingly said something in a group that amounted to an interesting observation. She pointed out that when she visited India after a long gap, she found that her husband's younger sister was wearing sleeveless shirts and shorts in her mother-in-law's presence, but "their rules were different from when I was of that age!" In-laws can maintain control even if they are living in India. The husband, in such cases, becomes the agent carrying out their wishes. One divorced woman told of her mother-in-law writing to her husband not to let her "evade his control," acting on the incitement of her husband's sister, who was staying with the couple at the time. As a result, the husband isolated his wife and beat her. Moreover, the kind of act, the context and setting in which it occurs, also carries legitimacy at times. If the respectful relationship with any of the in-laws is felt to have been violated, even in terms of showing independence by wearing 'western' dress, this may invite a negative reaction. Depending on the seriousness of the violation, acts of physical violence may win approval, with the degree of legitimacy and social support varying with the social, historical, and interpersonal parameters (Dobash and Dobash 1979).

In another case, however - that of a highly skilled working couple - it was actually the mother-in-law who helped the abused wife. This respondent was a professional working woman and the couple was earning very well. No one knew that she had been physically abused by the husband for quite some time. He used to get angry over minor things, even over a minor argument, and would beat her up. He used to wake her up in the night and throw her against the wall; she couldn't sleep properly for fear he might start again. Even though her maternal family relatives were in the United States, she did not tell them about the abuse so as not to be a burden. On one occasion, when her in-laws arrived from India and were staying with the couple, the husband started beating the wife in the presence of her mother-in-law. The motherin-law objected, but in spite of her efforts to stop him, the husband dragged the wife into another room and closed the door so he could continue beating her without interference. The mother-in-law wanted to call the police, but the father-in-law stopped her; instead, he called the wife's family to take her away for her own safety. With the support of her maternal family, this abused woman could finally obtain a divorce. She also changed her location and job, but it took quite a while to overcome depression.

Indian working women seldom kept separate bank accounts, though this is changing now among young professional immigrants. Earlier, women were not informed of financial matters, such as taxes, and as a result were more dependent on the husband. This can be observed particularly among women of the elder generation. The impact of role responsibilities from the home culture was strongest among them - with much time and attention devoted to performing the duties of a tradi- 
tional Indian wife and maintaining the family image in the eyes of the community. Interestingly, the 'others' also contribute to the construction of this image by contrasting the ethnic community practices with their own. In one case of financial and emotional abuse, the husband was swindling the wife's money and pressing her to take out loans. In spite of her being highly educated and holding down a job, she remained ignorant about her financial status for a long time and was unable to resist. When she realized that she had lost everything, she was in a fix. The respondent stated that though divorce was an option, it was hard to go down that road. Any hint of marital discord could easily become 'talk of the town' in the Indian immigrant community. Moreover, for middle-class working wives in the United States, filing for divorce is very expensive; lawyers, according to her, charge exorbitant fees, which would have the effect of further eroding her financial situation and depriving her of the money she would need after the divorce.

In most cases, the immigrant woman earns less than her husband. The husband has control over her pay and spending. The funds for her in-laws' air travel are typically taken from the woman's resources. Women tend to accept such practices for fear of causing conflict with family-kin. Incurring the displeasure of in-laws may result in gossip and criticism within the immigrant communities. One agitated interviewee commented, "We are filling their [meaning her in-laws in India] boriyans [meaning food grain containers or coffers] with dollars, and I cannot even buy underwear for myself. It's not only that you invite the husband's hostility if you don't comply, but because of being a badi-bahu [meaning the eldest daughter-in-law], the whole family-kin network expects you to make all kinds of sacrifices." Sometimes it is a thankless sacrifice.

\section{Isolation of Abused Migrant Women}

One elderly and physically handicapped woman pointed to another major factor related to domestic violence, namely isolation and dependency. Even though her abuse continued for years, she could not speak out for several reasons. Her husband, who held a prestigious government post, threatened her with political reprisals if she did so. She believed that her husband, because of his high position, would be able to make good on this threat. So she put up with physical and financial abuse as well as the trauma of having to witness an illicit relationship by her abusive husband in her own house. When she found out about her husband's infidelity, he grew even more violent. She described her humiliation when her husband not only thrashed her in front of the other woman, but seized her with both hands and told the other woman to slap her. With tears in her eyes she continued: “...but being a woman, bai-pan [implying a sense of the common sufferings of women] was awakened in the other woman and, luckily for me, she could not go through with it, so that at least I was spared further humiliation, though both made a point of treating me as a mental case, so I still had to endure their taunts and derisive laughter." And yet she was not 
ready to consider leaving her husband. "I can't drive a car ... so who can I depend on for even simple things like fetching groceries in this icy foreign land?" Here again it is apparent, despite the fact of her having lived in Canada for so many years, that there existed a construction of the 'other' in her mind. Dreamily, she expressed a wish that perhaps someday somebody would narrate her story in a film or a novel, and that after watching or reading it her husband would have a change of heart and come back to her! When this woman revealed her abuse to a small group of Indian immigrants involved in community social work, the husband became concerned about his own reputation in the community and at least stopped the physical part of the abuse. This brings out the potential for community pressure in stopping or reducing abuse. The Indian immigrant community in Canada has been observed to be more closely knit than in the United States, but this situation is slowly changing now due to the recent influx of well-off Indians from the Gulf states.

Another elderly woman, this time from an orthodox religious community, spoke out about her own abuse, and that of her daughters, at the hands of her husband. She reported that the community had advised her to go back to India because the abuser happened to be an important community leader and fundraiser for community causes. In this case, there was pressure coming from the community not to speak out about her problems because it was felt the community's reputation might suffer a setback. In some states of Northern India, extended family norms exert a controlling influence. Exposure of sexual abuse is still suppressed in some Indian immigrant communities. Many young men from these communities hold down security jobs that require night shifts. Under these circumstances, wives have to fear the father-inlaw who stays at home with them. He may make sexual advances toward them. They feel helpless, face constant tension, and cannot speak out.

In extreme cases, Indian immigrant women prefer legal intervention to going to shelters, according to social workers and some of the victims. This is largely a result of rigid thinking about being middle class. The immigrants do, in fact, come primarily from the middle class, which is seen as having a caste-like status. Women face the dilemma of losing their community status and support network if they leave their husband's house. Going to shelters or transition houses and then moving into public housing means a woman has to move away from her community. This presents an additional setback for Indian women who, as we have seen, are heavily dependent on their community and on networking with other immigrants from their home country. Immigrant women, to reiterate, see social isolation as something very difficult to bear. 


\section{Conclusion}

The policies of the North American countries, especially Canada, against domestic violence are generally more developed than in India. However, these policies do not appear to be meeting the complex needs of abused Indian immigrant women. Multiple layers of domination and other barriers keep these women in subjugation. It is essential to understand the dynamics of this subjugation process. The operant factors are family hierarchy, historical gender inequalities, plus the complexities and pressures that come from belonging to an ethnic community. However, in some cases at least, Indian immigrant women combine to prevent a further escalation of violence. Moreover, the role and impact of community cannot be ignored, even if it is imagined. Some studies have cautioned against strategies that directly challenge existing structures and beliefs, since these are likely to be regarded as culturally sensitive. Such strategies may even induce a backlash (Garg 2001; Kishwar 1999).

This research reinforces the important part played by belonging to family and community in the lives of Indian immigrants. The experiences of immigrant women show that they prefer intervention to come from within the family, rather than from state structures such as the police or shelter homes. Even back in India, a similar tendency is observed among abused women. For immigrants, there is a sense of belonging first to the family and then to the ethnic community. The problems facing immigrant Indian women need to be seen in this context. Therefore, the challenge for policymakers is to raise awareness of domestic violence within the immigrant communities themselves, and to establish networks of culturally specific institutions to support immigrant women. Strategies such as staging folk dramas during the Ganesh festival (a practice used earlier in India to subvert the colonial regime) or reviving the reformist tradition through community-based organizations (as has been done in Bengal or Maharashtra) can be useful in this regard. Active outreach by the Canadian and US governments to progressive elements within the immigrant community is also needed. More immediately, abused Indian women need to be linked up with facilities that provide social support and reduce isolation, rather than 'rescued' or removed from their abusive situation.

\section{Implications}

The gender roles of South Asian women and the barriers they face cannot be properly understood without unraveling the complex process of belonging to their own community and culture. As a result, Indian immigrant women find it difficult to access existing welfare benefits or to avail themselves of shelter and transition houses. There is a need to develop greater legal awareness and enlist community support when countering the domestic violence these women face. Existing accepted channels - such as those relating to community cultural activities - should be explored to ensure community support. This is essential in an era of increasing budget cuts to 
domestic abuse programs. Even so, current policies may not be sensitive enough to address the welfare needs of immigrant Indian women.

Several advocacy groups and activists are pressing for more changes in policies to counter the problem of violence against women. South Asian groups and activists, as well as leading feminists, have all stressed the need to understand diversity within the feminist movement. While agreeing that North American and particularly Canadian domestic violence policies are, on the whole, laudable, there is still an outstanding need to address the varied cultural experiences of Indian immigrant women.

\section{Future Research}

This exploratory research is necessarily limited by its small sample size. Yet the need to press on with binational research to understand women's needs in both India and North America is underscored by the study. Future research needs to keep in view the increasing scale of transnational migration and the challenges facing immigrants, not just in terms of settling into and adapting to their host countries, but also in terms of belonging to a home culture and community. A gender-sensitive analysis of the domestic violence issue could benefit policymakers by allowing them to create secure zones within the private space of Indian immigrant women. In an era of increasing transnational migration, this challenge needs to be addressed by researchers and policymakers alike.

\section{References}

Abraham, Margaret. 1999. "Sexual Abuse in South Asian Immigrant Marriages." Violence Against Women 5 (6): 591-618. doi:10.1177/10778019922181392. - 2000. Speaking the Unspeakable: Marital Violence among South Asian Immigrants in the United States. New Brunswick: Rutgers University Press. - 2005. "Domestic Violence and the Indian Diaspora in the United States." Indian Journal of Gender Studies 12 (2-3): 427-51. doi:10.1177/097152150 501200212.

Agnes, Flavia. 2000. "Women, Marriage, and the Subordination of Rights." In Community, Gender and Violence, edited by Partha Chatterjee and Pradeep Jeganathan, 106-37. New York: Columbia University Press. Ahuja, Ram. 1987. Crime Against Women. Jaipur: Rawat Publications. Alexander, M. J., and Chandra T. Mohanty. 1997. "Introduction: Genealogies, Legacies, Movements." In Feminist Genealogies, Colonial Legacies, Democratic Futures, edited by M. J. Alexander and Chandra T. Mohanty, xiii-xlii. New York: Routledge.

Anderson, Benedict. (1983) 2006. Imagined Communities: Reflections on the Origin and Spread of Nationalism. London: Verso. 
Anthias, Floya. 2006. "Belongings in a Globalising and Unequal World: Rethinking Translocations.” In The Situated Politics of Belonging, edited by Nira YuvalDavis, Kalpana Kannabiran, and Ulrike M. Vieten, 17-31. New York: Sage. Appadurai, Arjun. 1997. Modernity at Large: Cultural Dimensions of Globalization. New Delhi: Oxford University Press.

Bannerji, Himani. 2000. The Dark Side of the Nation: Essays on Multiculturalism, Nationalism and Gender. Toronto: Canadian Scholar's Press.

Bhattacharjee, Anannya. 1997. "The Public/Private Mirage: Mapping Homes and

Undomesticating Violence Work in the South Asian Immigrant Community." In Feminist Genealogies, Colonial Legacies, Democratic Futures, edited by M. J. Alexander and Chandra T. Mohanty, 308-29. New York: Routledge.

Busby, Cecilia. 1999. "Agency, Power and Personhood: Discourses of Gender and Violence in a Fishing Community in South India." Critique of Anthropology 19 (3): 227-48. doi:10.1177/0308275X9901900302.

Chanana, Karuna. 1996. "Introduction." In Women in Indian Society, edited by

A. M. Shah, B. S. Baviskar, and E. A. Ramaswamy, 13-32. New Delhi: Sage. Committee on the Status of Women in India. 1974. Towards equality: Report of the Committee on the Status of Women in India. New Delhi: Government of India. Dasgupta, Shamita D., and Sujata Warrier. 1996. "In the Footsteps of 'Arundhati': Asian Indian Women's Experience of Domestic Violence in the United States." Violence Against Women 2 (3): 238-59. doi:10.1177/107780129 6002003002.

Deolalikar, Anil B., and Vijayendra Rao. 1998. "The Demand for Dowries and Bride Characteristics in Marriage: Empirical Estimates for Rural South Central India." In Gender, Population and Development, edited by Maithreyi Krishnaraj, Ratna M. Sudarshan, and Abusaleh Shariff, 122-40. Delhi: Oxford University Press.

Derné, Steve. 1999. "Making Sex Violent: Love as Force in Recent Hindi Films." Violence Against Women 5 (5): 548-75. doi:10.1177/10778019922181365.

Desai, Neera, and Maithreyi Krishnaraj. 1987. Women and Society in India. Delhi: Ajanta Publications.

Dobash, R. E., and Russell Dobash. 1979. Violence against Wives: A Case against the Patriarchy. New York: Free Press.

___ (1978) 2005. "Wives: The "Appropriate" Victims of Marital Violence [Reprinted from Victimology: An International Journal].” In Violence Against Women: Classic Papers, edited by Raquel K. Bergen, Jeffrey L. Edleson, and Claire M. Renzetti, 168-83. Boston: Pearson.

Dube, Leela. 2001. Anthropological Explorations in Gender: Intersecting Fields. New Delhi: Sage.

Epstein, T. S. 1996. "Culture, Women and India's Development." In Social Structure and Change. Women in Indian Society, edited by A. M. Shah, B. S. Baviskar, and E. A. Ramaswamy, 33-55. New Delhi: Sage Publications. 
Fernandez, Marilyn. 1997. "Domestic Violence by Extended Family Members in India.” Journal of Interpersonal Violence 12 (3): 433-55. doi:10.1177/088626 097012003008.

Garg, Alice. 2001. "Countering Violence Against Women in Rajasthan: Problems, Strategies and Hazards.” Development 44 (3): 111-13. doi:10.1057/palgrave. development.1110275.

Gelles, Richard J. 1993. "Through a Sociological Lens: Social Structure and Family Violence." In Current Controversies on Family Violence, edited by Richard J. Gelles and Donileen R. Loseke, 31-46. Newbury Park: Sage.

Gelles, Richard J., and Murray A. Straus. 1988. Intimate Violence. The Causes and Consequences of Abuse in the American Family. New York: Simon and Schuster.

Heise, Lori L., Alanagh Raikes, Charlotte H. Watts, and Anthony B. Zwi. 1994. "Violence against Women: A Neglected Public Health Issue in Less Developed Countries." Social Science and Medicine 39 (9): 1165-79. doi:10.1016/ 0277-9536(94)90349-2.

Jejeebhoy, Shireen J. 1998. "Wife-Beating in Rural India: A Husband's Right? Evidence from Survey Data.” Economic and Political Weekly 33 (15): 855-62.

Johnson, Pamela S., and Jennifer A. Johnson. 2001. "The Oppression of Women in India." Violence Against Women 7 (9): 1051-68. doi:10.1177/1077801012218 2893.

Joshi, Khyati Y. 2006. New Roots in America's Sacred Ground: Religion, Race, and Ethnicity in Indian America. New Brunswick: Rutgers University Press.

Kakar, Sudhir. 1978. The Inner World: A Psycho-Analytic Study of Childhood and Society in India. Delhi: Oxford University Press.

Kallivayalil, Diya. 2010. "Narratives of Suffering of South Asian Immigrant Survivors of Domestic Violence.” Violence Against Women 16 (7): 789-811. doi: $10.1177 / 1077801210374209$.

Karlekar, Malavika. 1998. "Domestic violence." Economic and Political Weekly 33 (27): 1741-51.

Karve, Irawati. 1965. Kinship Organization in India. Bombay: Asia Publishing House.

Kelkar, Govind. 1992. Violence Against Women: Perspectives and Strategies in India. Shimla: Indian Institute of Advanced Study.

Kishwar, Madhu. 1999. Off the Beaten Track: Rethinking Gender Justice for Indian Women. New Delhi: Oxford University Press.

Koh, Sin Y. 2011. "The Sceptical Citizen, The Mobile Citizen, and The Converted National: Chinese-Malaysians in Singapore Negotiating 'Skilled Diasporic Citizenship.'” Paper presented at the International RC21 conference 2011 "The Struggle to belong. Dealing with diversity in 21 st century urban settings." Accessed September 26, 2017. http://www.rc21.org/conferences/amst erdam2011/edocs/Session\%2019/RT19-1-Koh.pdf. 
Kumar, Radha. 1993. The History of Doing: An Illustrated Account of Movements for Women's Rights and Feminism in India, 1800-1990. New Delhi: Kali for Women.

Kumari, Ranjana. 1989. Brides Are Not for Burning: Dowry Victims in India. New Delhi: Radiant Publishers.

Liddle, Joanna, and Rama Joshi. 1986. Daughters of Independence: Gender, Caste and Class in India. London: Zed Books.

Madan, T. N. 1975. "Structural Implications of Marriage in North India." Contributions to Indian Sociology 9 (2): 217-43. doi:10.1177/0069966775009 00204.

Mahajan, A. 1990. "Instigators of Wife Battering." In Violence Against Women, edited by Sushma Sood, 1-10. Jaipur: Arihant Publications.

METRAC (Metropolitan Action Committee on Violence Against Women and Children). 2001. "Statistics Sheet: Sexual Assault." http://www.metrac.org/ new/stat_sex.htm (accessible via archive.org).

Mukherjee, Chandan, Preet Rustagi, and N. Krishnaji. 2001. "Crimes Against Women in India: Analysis of Official Statistics." Economic and Political Weekly 36 (43): 4070-80.

Pillai, Suma. 2001. "Domestic Violence in New Zealand: An Asian Immigrant Perspective." Economic and Political Weekly 36 (11): 965-74.

Preisser, Amita B. 1999. "Domestic Violence in South Asian Communities in America." Violence Against Women 5 (6): 684-99. doi:10.1177/1077801 9922181437.

Raheja, Gloria G., and Ann G. Gold. 1996. Listen to the Heron's Words: Reimagining Gender and Kinship in North India. Delhi: Oxford University Press.

Raj, Anita, and Jay G. Silverman. 2007. "Domestic Violence Help: Seeking Behaviors of South Asian Battered Women Residing in the United States." International Review of Victimology 14 (1): 143-70. doi:10.1177/0269758007014 00108.

Rao, Vijayendra. 1998. "Wife Abuse, Its Causes and Its Impact on Intra-Household Resource Allocation in Rural Karnataka: A 'Participatory' Econometric Analysis." In Gender, Population and Development, edited by Maithreyi Krishnaraj, Ratna M. Sudarshan, and Abusaleh Shariff, 94-121. Delhi: Oxford University Press.

Sakal Daily. 2001. "Government shelters are like brothels: Justice Usha Mehra's comments." February 23, p.3.

Segady, Thomas W., and Swati Shirwadkar. 2012. "The Changing of the Gods: Religion, Religious Transformation and the Indian Immigrant Experience." Sociology Mind 2 (4): 428-34. doi:10.4236/sm.2012.24055.

Segal, Uma A. 1999. "Family Violence: A Focus on India." Aggression and Violent Behavior 4 (2): 213-31. doi:10.1016/S1359-1789(97)00051-7.

Shirwadkar, Swati. 1998. Women and Socio-Cultural Changes. New Delhi: Gyan Publishing House. 
. 2004. "Canadian Domestic Violence Policy and Indian Immigrant Women.” Violence Against Women 10 (8): 860-79. doi:10.1177/10778 01204266310.

Singh, Yogendra. 2000. Culture Change in India: Identity and Globalization. Jaipur: Rawat Publications.

Srinivas, Mysore N. 1978. The Changing Position of Indian Women. Delhi: Oxford University Press. The T.H. Huxley memorial lecture delivered at the London School of Economics 1976.

Status of Women Canada. 2002. "Assessing Violence Against Women: A Statistical Profile.” Accessed January 18, 2018. http://publications.gc.ca/collections/Col lection/SW21-101-2002E.pdf.

The Lawyers Collective. 2001. "Women's rights initiative." Accessed November 15, 2003. www.lawyerscollective.org/wri/activities/research_documentation/ domestic_violence/wri_domesticviolence_campaignforcivillaw.htm (accessible 2018 via archive.org).

Uberoi, Patricia. 2000. "The Family in India: Beyond the Nuclear Versus Joint Debate." Occasional Papers in Sociology, Delhi: Institute of Economic Growth.

Yuval-Davis, Nira. 2006. "Belonging and the Politics of Belonging." Patterns of Prejudice 40 (3): 197-214. doi:10.1080/00313220600769331. 